\title{
How Live-streaming Has Been Utilized to Function on the Market of E-commerce in Recent China
}

\author{
Jinyue Zhu \\ Department of Cinema \& Media Studies, University of Washington, Seattle, 98195, US, jinyue0724@163.com

\begin{abstract}
Nowadays, the lives-streaming function pervades people's life gradually. This paper mainly discusses how livestreaming could take advantage of its specialities on e-commerce platforms. Based on research and the interviews analysis, this study shows how the marketers utilize this function as a marketing strategy to stimulate consumers' purchasing intention in three different aspects: the concept of ecommerce + live-streaming, pushed live-streaming option to target consumers, and the emotional connection between streamers and consumers.
\end{abstract}

Keywords: Live streaming, Marketing Strategies, E-commerce, Purchasing Intention.

\section{INTRODUCTION}

Many online companies believe that live-streaming stimulates purchasing power and influences people's buying choices online. Whether it actually does or not has great practical significance to online companies. Nevertheless, the relationship between online consumers and information on the internet - live-streaming or not - is complex and interdependent. Live-streaming, which is a new function that online users get familiar with in recent years, has gradually become a part of social life and is also used as a marketing tool. This function vague the boundaries between online and offline lives since it provides the opportunity to engage in real-time and twoway communication. With or without notice, the livestreaming might influence each individual's purchase intentions. This research paper seeks to understand how effectively this new media promotes products and pushes the development of E-commerce in recent China. Readers could better understand how live-streaming plays a role in their daily lives, and how information that appears online directly or indirectly shifts their way of thinking.

\section{LITERATURE REVIEW}

Since E-commerce gradually replaced traditional physical stores nowadays, the boom of live- streaming shifts the methods merchants used to promote their products and influences consumers' purchasing intentions in recent China. An empirical study that focuses on the influencing factors of e-commerce live streaming conducted by Su takes Taobao as an example, bringing up the concept of the "Live streaming + Ecommerce" model [1]. It uses LP commercial broadcast models to analyze live streaming from five aspects: perceived ease of use, perceived usefulness, perceived fun, social presence, and "immersive" experiences to demonstrate the reason why live broadcasting ecommerce is so popular and successful. Moreover, the merchants understand what advantages they could take on from the live-streaming to strengthen marketing stimulation based on these five aspects, such as enhancing the perception of interest to achieve the goal of drainage, and a sense of social existence to affect users' reusing behavior [1]. Sun et al. use survey methods to demonstrate the implications of IT affordance for social commerce, which discusses how visibility affordance, metavoicing affordance, and guidance shopping affordance significantly impact customer purchase intention through live-streaming engagement, which provides the basic ideas to understand the unique features of live-streaming and use empirical evidence to show how live-streaming connects to consumers [2].

In order to address the essential factors behind the boom of live-streaming e-commerce, two studies that respectively use a proposed conceptual model and elaboration likelihood model (ELM) further analyze the special relationship between live-streaming and consumers. Gao et al. research self-determination theory and use the model results to show how telepresence, social presence, relatedness, and autonomy relate to consumers' psychological needs, which shape consumers' attitudes and purchase intention afterward [3]. In addition, Chen et al. illustrate how more trust in the streamer 
influences more trust in the product in the live-streaming commerce [4]. Both of them explore the special connection ties between streamers and consumers by focusing on the perspective of psychology.

Based on the facts provided above, the specialty of live-streaming is utilized as a new market strategy to engage in the interaction between the marketers and consumers. They are analyzing practical marketing tactics, which associate with the live-streaming feature, will gain more insight to understand why consumers have more intention to buy products they originally were not expected to buy while watching live-streaming. The study carried out by Hou et al. uses mixed-methods research to show that consumption intention influence by the social status display and sex appeal, which form the strategy that could improve streamers' live-streaming platform's popularity and profitability [5]. This study displays the rules marketers utilize to hire streamers in general to attract hit rate. Furthermore, based on monthly average cross-sectional data and classical regression analysis, Geng et al. estimate the effects of internet celebrity endorsement on sales performance and online store popularity [6]. It concludes that endorsement could transfer to real economic value offline. The empirical results show that the "content generation efforts of marketers and the interaction behaviors between marketers and consumers will significantly influence ecommerce sales" [6].

\section{RESEARCH QUESTION}

RQ1: Why do people make the purchase decision while watching live streaming?

RQ2: How do merchants intentionally take the advantages of live streaming to affect consumers purchasing decisions?

\section{METHODS}

In order to use more credential resources to analyze the impact of live-streaming on online purchase behaviors, this study uses the data from the CNNIC investigation report of The 47th China Statistical Report on Internet Development that the China Internet Network Information Center released [7]. Also, this study conducted qualitative interviews with open-ended interview questions, which included the five interviewees who are now undergraduate students in the Chinese Colleges and five interviewees who are now undergraduate students overseas. This research paper extracted and summarized the important information of these direct interviews with questions around the research topic based on online phone call recordings. The respondents' personal experiences would provide more meaningful and in-depth information for further analyzing the research questions.

\section{FINDINGS}

In recent China, live-streaming is a tool for people to have closer relationships via a wireless internet connection and a marketing strategy for marketers to promote their products. Based on the meaningful information of the interviews and the data analysis of the CNNIC report, this study found that live-streaming has a significant impact on the consumers online purchasing intentions and increases consumption behaviors.

Unlike traditional marketing strategies, e-commerce utilizes those unique advantages generated by the livestreaming functions, becoming standing out conspicuously in this fast-developing social media landscape. Referring to the concept of "Live streaming + E-commerce" model, live-streaming functions reach out to various media platforms and become a new way for product promotion. In China's famous e-commerce trading platforms and social media platforms such as Taobao, Kuaishou, and Douyin, these platforms gather countless small individual e-commerce merchants that almost satisfy everything consumers need, and transactions are conducted independently between individuals and merchants in the trading platform. Livestreaming functions in these platforms successfully develop the new digital economy model of "online drainage, physical consumption" [7]. From watching the live-streaming toward making the purchase decision, it forms a new trend which gradually becomes popular in people's daily lives. Data show that $66.2 \%$ of live broadcast users have purchased products during the ecommerce live broadcast, and $17.8 \%$ of the users' consumption amount in e-commerce live broadcast accounted for three times more than all their online shopping consumption amount [7].

Based on the interviews and observation, there are three significant ways to lead the interaction between the online users and live-streaming. Firstly, take major ecommerce trading platforms as an object of study. Each online merchant stores hold their independent livestreaming room, which will appear on the sidebar of their shopping site. The given streamers would introduce their featured product. All the respondents of interviews state that they have watched the live-streaming of their exciting products when the live-streaming is available on the selling pages because it helps them learn more about the products. Live-streaming offers an opportunity for consumers to see the visualized products. The visibility affordance helps viewers obtain more information from the synchronized viewing experience. Also, direct communication between customers and streamers provides consumers a friendly impression, and narrow the perceived distance between consumers and streamers [8]. Guidance shopping affordance lets streamers efficiently provide the direct service during the livestreaming by focusing on personalizing needs and interests. Pan and Liao, two of the interview respondents, 
indicate they always leave the message while livestreaming to consult about the size of the products or ask the streamers to try certain products to see the practical effects. Three other interviewees say that the chatting history between the streamers and other online shoppers always provides sufficient information before making purchase decisions. Moreover, these three IT affordances associated with live streaming features lead viewers to perceive immersion and perceive social presence via active interaction between the streamers and viewers [2]. Wang, one of the respondents, regards the feeling of entering a specific store's broadcast room as similar to entering an offline store. She holds the great extent of autonomy to take the initiative to browse products according to her own needs and requirements. Social presence provided by the shopping website can satisfy consumers' relatedness needs and increase stickiness, while perceived immersion can significantly increase consumers' intention to buy through autonomy and stickiness [3]. Therefore, the sense of participation generated from the live-streaming features might increase Wang's social presence and highly enhance the participation rate during the buying process.

Inadvertently browsing the live-streaming will stimulate people's desire for immediate consumption. The cooperative relationship between social media platforms and e-commerce platforms enables customers to place an order without using complicated procedures and lower prices. All the research respondents show that they have the experience to click into the link of recommendation live-streaming, which usually shows up when customers randomly go through social media. Those live-streaming options will be sent to potential customers and precisely target each individual based on the viewing history and algorithm. When people quickly browse social platforms, the live-streaming will send to the viewers the same as the way to push advertisements so that it is easy to attract the attention of potential customers. Plus, the contents of live-streaming target potential customers precisely, so this might be the reason why most of the respondents feel not averse to spending a few seconds to learn the product. All interviewees indicate that the attractive promoting products in livestreaming on some social media are like serendipity. Liu, Pan, and Liao are three respondents inclined to make impulsive consumption when they look through social media. They state that the products promoted in livestreaming have significant discounts and are very cheap most of the time, and this is a significant common factor to drive them to make consumption decisions quickly. "Because I feel that I may need it, and it is very cheap, sometimes with a $50 \%$ discount, so I often place an order without hesitation," Pan tells her purchase experience excitedly. For example, stocking up a large amount of paper and daily-use products is usually cost-effective. Also, according to Liu's experience, she states that it is possible to encounter unsatisfactory products, but it does not affect her consumption impulse. "There will always be a suitable one among a large number of orders. I do not care a lot because they are all very cheap". Therefore, the convenience and discount provided by live broadcast might stimulate the consumption intention when people play on their phones and randomly go through social media.

The factors that make Live-streaming so successful in e-commerce depend on the unique relationships established between the consumers and merchants. Consumers' higher trust in streamers can transfer to a higher trust in products, further influencing consumers' purchase intention and loyalty behavior. Both trust in products and trust in streamers would affect consumers' willingness to pay more [4]. Trust in streamers will lead people to do a spontaneous search and watch the livestreaming held by certain streamers, which might increase the stickiness between brands and potential customers. Two interviewees show that they have a specific favorite brand broadcast room, and three interviewees show that they would regularly watch the live-streaming hosted by specific streamers. Rao indicates that it is unusual to do online shopping simply because of streamers, but she always regards the products shared by her favorite streamers as trustworthy. Good quality products collaborating with famous streamers can create sales miracles in live-streaming commerce [4]. According to one SupChina news 2020 [14], one of the well-known Chinese live streamers Viya, could make more profit in one day (Single's Day 2019, \$385 million) than Aston Martin does in one year. Her sales figures and viewing rates are staggering, and every interview respondents show that they know this famous live streamer. Viya always uses her unique persuasive speaking skills to show her knowledge and let the audience know the quality through the practical operation. The high performance on the live-streaming sale made her an internet celebrity; her appeal and public praise are the critical factors to determine her future success. "Content marketing with internet celebrity endorsements plays a deterministic role in directing and increasing traffic to e-commerce retailers, and internet celebrity endorsement significantly boosts the sales performance of e-commerce retailers" [6].

\section{CONCLUSION}

Based on the interviews, the three situations that drive people to consume more do not have apparent differences among students studying in China and studying abroad. The impact of live streaming on shopping intentions may have a lot to do with the frequency they get in touch with live-streaming and varied purchase power. In addition, the slight difference between these two study groups might come from the time and the energy they put into those big social media platforms. With more time online users spend looking through social media, more pop-out live-streaming will come out, which increases the 
probability of online shopping. The study did not include gender as a factor, but it is still helpful in analyzing the impact of live streaming on potential customers. The experience analysis and fact analysis of the interviewees reflect a great extent of the current online consumption of Chinese netizens. Overall, the unique advantages generated by the live-streaming, the convenience, and the discounts brought by the cooperative relationship between e-commerce and live streaming, and the relationship established between the live streamers and the viewers are three driving factors to lead people to consume more. For merchants who try to use the live broadcast to promote their products, they could increase sales through enhancing people's viewing experience, connecting big social media platforms for online drainage, or hiring a talented streamer.

\section{REFERENCES}

[1] Su, X. (2019). An empirical study on the influencing factors of e-commerce live streaming. 2019 International Conference on Economic Management and Model Engineering (ICEMME). doi :10.1109/icemme49371.2019.00103

[2] Sun, Yuan, Shao, Xiang, Li, Xiaotong, Guo, Yue, \& Nie, Kun. (2019). How live streaming influences purchase intentions in social commerce: An IT affordance perspective. Electronic Commerce Research and Applications, 37, 100886.

[3] Gao, Wei, Liu, Yamei, Liu, Zhaopeng, \& Li, Jingyuan. (2018). How does presence influence purchase intention in online shopping markets? An explanation based on self-determination theory. Behaviour \& Information Technology, 37(8), 786799.

[4] Chen, Chun-Der, Zhao, Qun, \& Wang, Jin-Long. (n.d.). How livestreaming increases product sales: Role of trust transfer and elaboration likelihood model. Behaviour \& Information Technology,Ahead-of-print(Ahead-of-print), 1-16.

[5] Hou, Fangfang, Guan, Zhengzhi, Li, Boying, \& Chong, Alain Yee Loong. (2019). Factors influencing people's continuous watching intention and consumption intention in live streaming. Internet Research, 30(1), 141-163.

[6] Geng, Ruibin, Wang, Shichao, Chen, Xi, Song, Danyang, \& Yu, Jie. (2020). Content marketing in e-commerce platforms in the internet celebrity economy. Industrial Management Data Systems, 120(3), 464-485.

[7] The 47th China Statistical Report on Internet Development (47th ed., Rep.). (2021). China Internet Network Information Center.
[8] Lv, Z., Jin, Y., Huang, J., 2018. How do sellers use live chat to influence consumer pur-

chase decision in China? Electron. Commer. Res. Appl. 28, 102-113. https://doi.org/

10.1016/j.elerap.2018.01.003.

[9] Pan, S. (2021, May 2). How Live-streaming Influence Purchase Intention [Telephone interview].

[10] Liao, X. (2021, May 2). How Live-streaming Influence Purchase Intention [Telephone interview].

[11] Wang, J. (2021, May 2). How Live-streaming Influence Purchase Intention [Telephone interview].

[12] Liu, Y. (2021, May 2). How Live-streaming Influence Purchase Intention [Telephone interview].

[13] Rao, H. (2021, May 2). How Live-streaming Influence Purchase Intention [Telephone interview]

[14] Colville, A. (2021, May 03). Viya, China's most popular (and HARDEST-WORKING) LIVESTREAMER. Retrieved May 09, 2021, from https://supchina.com/2020/07/06/viya-chinas-mostpopular-and-hardest-working-livestreamer 